\title{
A REVIEW ON OVERVIEW OF WORLDWIDE INTEROPERABILITY FOR MICROWAVE ACCESS (WIMAX) INNOVATION AND ITS FUTURE UTILIZATIONS
}

\author{
Savita Yadav ${ }^{1}$, Kapil Kumar ${ }^{2}$, Rashmi $^{3}$, Neera Agarwal ${ }^{4}$ and Amit Dixit ${ }^{5}$ \\ ${ }^{1,2}$ Department of Electronics and Communication Engineering, Sanskar College of Engineering and Technology, India \\ ${ }^{3}$ Department of Computer Science Engineering, Delhi College of Technology and Management, India \\ ${ }^{4}$ Department of Electronics and Communication Engineering, Bharti Vidyapeeth College of Engineering, India \\ ${ }^{5}$ Department of Electronics and Communication Engineering, Quantum University, India
}

\begin{abstract}
This paper introduces the elements of the Worldwide Interoperability for Microwave Access (WiMAX) innovation and future utilizations of WiMAX. It is a connection oriented wireless network that assures Quality of Service (QoS) for all users in the network. By comparing WiMAX with the popular Wi-Fi, $3 G$ and LTE in the market, it analyzes the current situation and future development trend of WiMAX in terms of the difference in technology and applications. WiMAX will become the most prominent technology for Broadband Wireless Access (BWA). The next generation WMAN networks, using the WiMAX as the core technology is evolving as a $4 G$ technology for providing ubiquitous computing solutions. In not a similar way like wireless LANs, WiMAX networks integrate various QoS mechanism at the Media Access Control (MAC) level for secured service for voice, data and video. The unique architecture of the WiMAX MAC and PHY layer that uses OFDMA to allocate multiple channels with different modulation schemes. A few references have been incorporated towards the completion of this paper for those eager to know in brief about certain points.
\end{abstract}

Keywords:

WiMAX, QoS, OFDMA, IEEE802.16, MAC

\section{INTRODUCTION}

WiMAX is an IP based wireless broadband access innovation that gives execution like $802.11 / \mathrm{Wi}-\mathrm{Fi}$ systems with the scope and QOS (Quality of service) of cell systems. WiMAX is additionally an acronym signifying "Worldwide Interoperability for Microwave Access (WiMAX). WiMAX is a wireless digital communication system, otherwise called IEEE 802.16 that is planned for wireless "Metropolitan Area Network". WiMAX can give Broadband Wireless Access (BWA) up to 30 miles $(50 \mathrm{~km})$ for fixed stations, and $3-10$ miles $(5-15 \mathrm{~km})$ for mobile stations. Conversely, the Wi-Fi/802.11 wireless neighborhood standard is restricted much of the time to just $100-300$ feet $(30-100 \mathrm{~m})$. WiMAX works on both licensed and non-licensed frequencies, giving a controlled domain and reasonable monetary model for remote bearers. The normal cell ranges for most WiMAX systems will probably boast 4-5 mile extend (in NLOS capable frequencies) even through tree cover and building dividers. Service runs up to 10 miles (16km) are likely in Line-of-Sight (LOS) applications (indeed relying on frequency). Mobile WiMAX capacities on a for each client premise are widely improved than contending $3 \mathrm{G}$ innovations. WiMAX is regularly referred to have a spectral effectiveness of $5 \mathrm{bps} / \mathrm{Hz}$, which is great in contrast with other broadband wireless innovations, particularly $3 \mathrm{G}$ [13].

\subsection{WILL WIMAX SUBSTITUTE FOR DSL AND CABLE?}

It is imperative to recall that WiMAX is a worldwide broadband wireless standard. The subject of regardless of whether it could substitute for either DSL or Cable will differ from place to place. Many developing nations basically don't have the system to help either link or DSL broadband innovations. Actually, numerous such nations are already widely utilizing exclusive broadband remote advancements. Indeed, even in such locales anyway, it is exceptionally far-fetched that either Cable or DSL advancements would vanish. The business cases and fundamental foundations frequently manage that the least expensive arrangements will prevail. In numerous ranges in developing countries, it might be less expensive to send Cable and DSL in the urban areas in any event for fixed applications, though WiMAX will rule outside of significant towns. This offers a convincing contention that low- cost WiMAX apparatus can use access to some new clients. WiMAX additionally guarantees an unheard of level of information access adaptability that will be significantly less area specific for clients. Furthermore, WiMAX will give competitive choices to transporters and clients that will profit conventional wire line transporters and clients by empowering development and enhanced administrations. With the coming of IPTV fiber plays appreciating resurgence. It does not appear that WiMAX or broadband remote will be prepared to convey IPTV in the prompt future. However, fixed WiMAX may offer the best potential for conveyance of this potential substance juggernaut. More recently some encouraging new compression advancements have achieved the market. These advances, while still new, permit the conveyance of genuine IP-based TV signs to cell gadgets. One organization affirms that it could convey High Definition TV (HDTV) in as little as $2.5 \mathrm{Mbps}$ of transfer speed, with standard resolution signal requirement of $1.5 \mathrm{Mbps}$. These speeds are inside the potential reach of WiMAX. Qualcomm and its MediaFlo system are one great example of such innovations. Note that the resolution of this TV or video framework is not at the level of standard TV, but rather advance is happening rapidly.

\subsection{IEEE 802.16}

The IEEE built up the 802.16 in its first form to address Line of Sight (LOS) access at spectrum ranges from $10 \mathrm{GHz}$ to $66 \mathrm{GHz}$. The innovation has advanced through a few updates to the standard, for example, 802.16a, 802.16c, the Fixed WiMAX 802.16d (802.16-2004) determination and in conclusion the versatile $802.16 \mathrm{e}$ set that are at present financially accessible. The upcoming $802.16 \mathrm{~m}$ standard is expected to be endorsed in 2010 . The main update included help for $2 \mathrm{GHz}$ through $11 \mathrm{GHz}$ range 
with NLOS ability. Each refresh included extra usefulness or extended the scope of the standard. For instance, the 802.16c amendment included help for spectrum ranges both licensed and unlicensed from $2 \mathrm{GHz}$ to $10 \mathrm{GHz}$. It also enhanced nature of Quality of Service (QOS) and certain changes in the media access control (MAC) layer alongside including support for the HiperMAN European standard. The number of supported physical (PHY) layers were expanded. Transport mediums, for example, IP, Ethernet and Asynchronous Transfer Mode (ATM) were included. Concentrated in 2-to-11GHz WMAN, with the following arrangement of elements:

- Service area range $50 \mathrm{~km}$

- NLoS

- QoS designed in for voice/video, differential services

- Very high range spectrum utilization: $3.8 \mathrm{bit} / \mathrm{Hz}$

- Up to 280Mbps per BS

- Speed - 70Mbps.

\subsection{WIMAX-DEVELOPMENT TECHNOLOGY}

\section{OF THE}

As the imagined usage scenarios have developed over time, so have developed the technological premises of WiMAX. The IEEE 802.16 technical group has now developed through three generations [1]. The comparison among these three generations are given in the Table.1. They are differ from each other by their uses and connectivity.

Table.1. Comparison between IEEE 802.16 Generation

\begin{tabular}{|c|c|c|c|}
\hline \multirow{2}{*}{$\begin{array}{c}\text { Parameters for } \\
\text { Comparison }\end{array}$} & \multicolumn{2}{|c|}{ IEEE 802.16-2004 } & \multirow{2}{*}{$\begin{array}{c}\text { IEEE } \\
\text { 802.16e }\end{array}$} \\
\hline & IEEE802.16 & IEEE802.16a & \\
\hline Spectrum & $10-66 \mathrm{GHz}$ & $2-11 \mathrm{GHz}$ & $<6 \mathrm{GHz}$ \\
\hline Configuration & LOS & NLOS & NLOS \\
\hline Bit Rate & 32-134Mbps & 70-100Mbps & $15 \mathrm{Mbps}$ \\
\hline Modulation & $\begin{array}{c}\text { QPSK,16- } \\
\text { QAM,64-QAM }\end{array}$ & $\begin{array}{c}256 \text { sub } \\
\text { carrier OFDM } \\
\text { using } \\
\text { QPSK,16- } \\
\text { QAM,64- } \\
\text { QAM,256- } \\
\text { QAM }\end{array}$ & $\begin{array}{c}2048 \text { sub } \\
\text { carrier } \\
\text { OFDMA } \\
\text { using } \\
\text { QPSK,16- } \\
\text { QAM,64- } \\
\text { QAM,256- } \\
\text { QAM }\end{array}$ \\
\hline Mobility & Fixed & Fixed & $\begin{array}{c}\text { Approx. } 130 \\
\mathrm{Km} / \mathrm{h}\end{array}$ \\
\hline $\begin{array}{c}\text { Channel } \\
\text { Bandwidth }\end{array}$ & $20,25,28 \mathrm{MHz}$ & $\begin{array}{c}\text { Selectable } \\
1.25 \text { to } \\
20 \mathrm{MHz}\end{array}$ & $5 \mathrm{MHz}$ \\
\hline Cell Radius & $1-5 \mathrm{~km}$ & $45 \mathrm{~km}$ & $1-5 \mathrm{~km}$ \\
\hline Uses & $\begin{array}{c}\text { Lost-mile } \\
\text { broadband } \\
\text { access, SOHO } \\
\text { etc }\end{array}$ & $\begin{array}{l}\text { Alternative to } \\
\text { DSL, VoIP etc }\end{array}$ & $\begin{array}{l}\text { QoS based } \\
\text { application }\end{array}$ \\
\hline
\end{tabular}

\subsection{WIMAX SYSTEM}

A WiMAX system comprises of two sections:
- A WiMAX tower - comparable in idea to a phone tower-A single WiMAX tower can give scope to a vast region as large as 3,000 square miles ( 8,000 square $\mathrm{km})$.

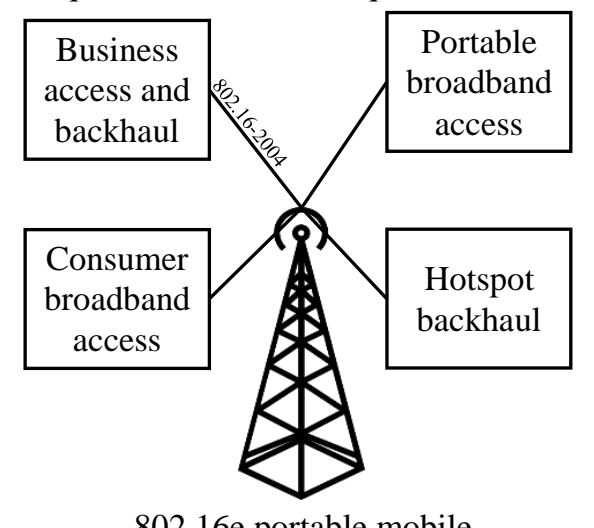

802.16e portable mobile

Fig.1. WiMAX Tower

- A WiMAX receiver - The receiver and antenna could be a little box or PCMCIA card, or they could be incorporated with a tablet the way that Wi-Fi access is today.

A WiMAX tower station can interface specifically to the Internet utilizing a high transmission capacity, wired association (for instance, a T3 line). It can also associate with another WiMAX tower utilizing an LOS, microwave interface. This association with a moment tower (frequently referred to as a backhaul), alongside the capacity of a signal tower to conceal to 3,000 square miles, is the thing that enables WiMAX to give scope to remote country territories. Contrasted with the complicated wired system, a WiMAX system just comprises of two sections:

The WiMAX base station (BS) and WiMAX subscriber station (SS), also known to as customer premise equipment (CPE). Thusly, it can be fabricated rapidly at low cast. At last, WiMAX is also considered as the next step in the mobile innovation advancement path. The potential combination of WiMAX and CDMA standards are referred to as 4G [15].

\subsection{SYSTEM MODEL}

IEEE 802.16 supports two methods of operation: PTP and PMP.

\subsubsection{Point-To-Point (PTP):}

The PTP interface refers to a dedicated connection that associates just two hubs: BS and subscriber terminal. It uses resources in an efficient way and considerably causes high operation costs. It is typically just used to serve high-value clients who require to a great degree high bandwidth, for example, business high rises, video postproduction houses, or scientific research associations. In these cases, a signal association contains all the accessible data transmission to create high throughput. A highly directional and high-gain antenna is also important to limit interference and maximize security.

\subsubsection{Point-To-Multipoint (PMP):}

The PMP topology, where a group of subscriber terminals are associated with a BS independently (shown in Fig.2), is a superior 
decision for clients who don't have to utilize the whole transfer speed.

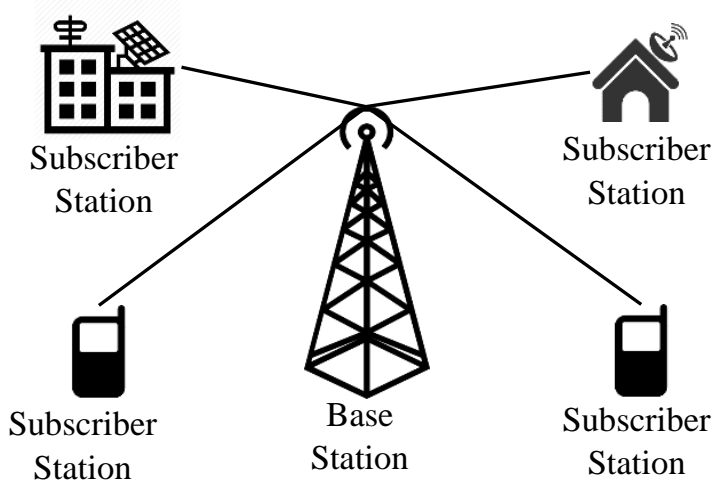

Fig.2. PMP Technology

Under PMP topology, sectoral antenna with highly directional parabolic dishes (each dish refers to sector) are utilized for frequency reuse. The accessible transmission capacity now is shared between a group of clients, and the cost for every subscriber is decreased.

\subsubsection{Mesh Topology:}

In addition to PTP and PMP, 802.16a present the mesh topology, which is a more adaptable, effective, reliable, and convenient system design in view of the multihop idea, which is shown in Fig.3. Mesh networks are wireless data network that give the SSs more intelligence than traditional wireless.

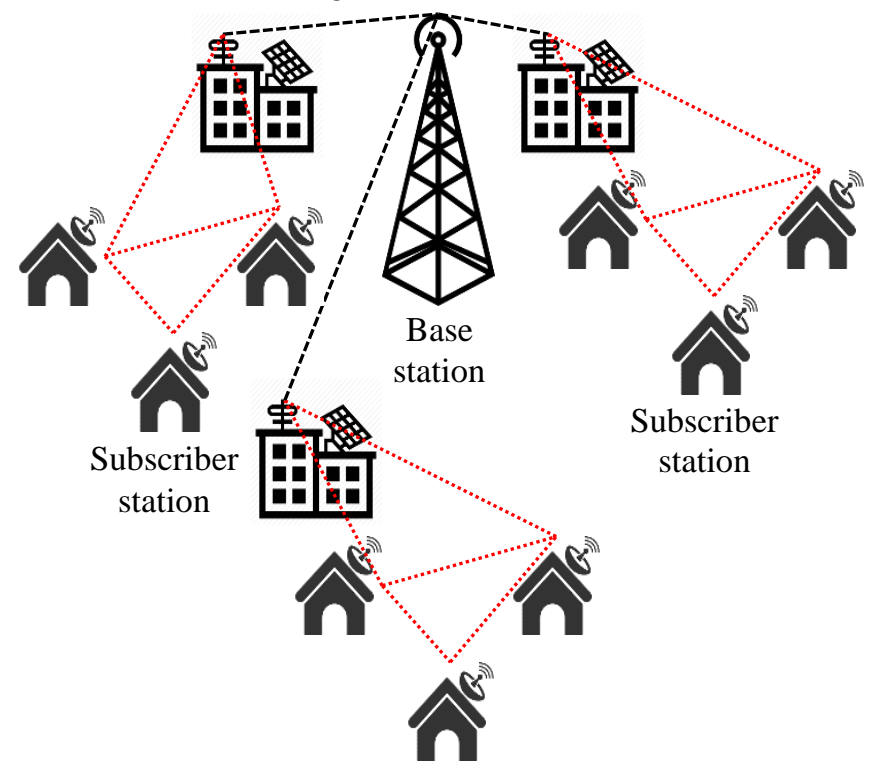

Subscriber station

Fig.3. Mesh Topology

Transmitters and recipients. In a PMP network, every one of the associations must experience the $\mathrm{BS}$, while with mesh topology, each SS can go about as an access point and can route packets to its neighbors without anyone else to amplify the geographical coverage of a network. The design of a mesh network is shown in Fig.3. The routing over the system can be either proactive (utilizing foreordained directing tables) or responsive (producing routes on request) [2].

\section{WIMAX AS A METRO-ACCESS}

Deployment Option: WiMAX is an overall certification tending to interoperability across IEEE 802.16 standard based items. The IEEE 802.16 standard with particular updates tends to two use models:

- Fixed (IEEE 802.16d)

- Portable (IEEE 802.16e)

\subsection{FIXED (IEEE 802.16D)}

Fixed WiMAX is the $802.16 \mathrm{~d}$ standard or as it is sometimes called 802.16-2004. Its product profile uses the OFDM 256-FFT (Fast Fourier Transform) system profile, which is sufficiently not quite the same as its sister standard of Mobile WiMAX (802.16e) that the two are contrary. Strikingly, the two norms support the two protocols inside the innovation protocol and in addition the one decided for Mobile WiMAX and the Korean WiBro/Mobile WiMAX standard. In the event that the Forum had chosen to utilize an OFDMA form in Fixed WiMAX, it would have been far simpler to give an upgrade path. This specific disengage likely indicates the rising comprehension of the commercial center energy of WiMAX. All the more vitally, it demonstrates the energy of the Korean WiBro/Mobile WiMAX influence, which intensely impacted the utilization of OFDMA ${ }^{\circledR}$ in the Mobile Standard . The Fixed WiMAX 802.16-2004 standard supports both time division duplex (TDD) and frequency division duplex (FDD) administrations - the last of which is much more prevalent with portable remote suppliers than the more up to date TDD approach. Now, Fixed WiMAX 802.16d networks are broadly conveyed in both Europe and Asia, however obviously for some merchants the appropriation of the Mobile WiMAX 802.16e is the alternative of decision. As already discussed, the opening of the US $3.65 \mathrm{GHz}$ range go has opened up a $802.16 \mathrm{~d}$ chance in the US as sellers adjust existing $3.5 \mathrm{GHz}$ systems (and generally Fixed WiMAX based worked for International utilize) radio systems to use in this band.

\subsection{PORTABLE (IEEE 802.16E)}

The portable Mobile WiMAX standard of $802.16 \mathrm{e}$ is different from Fixed WiMAX. It attracted in a significant number of Forum individuals towards a chance to substantively challenge existing $3 \mathrm{G}$ innovation purveyors. While plainly in light of the same OFDM base innovation received in 802.16-2004, the 802.16e variant is intended to convey benefit crosswise over numerous more sub-channels than the OFDM 256-FFT. It is vital to take note of that the two measures support single carrier, OFDM 256FFT and in any even OFDMA 1K-FFT. The 802.16e standard includes OFDMA 2K-FFT, 512-FFT and 128-FFT capacity. Subchannelization encourages access at different separation by giving administrators the capacity to progressively diminish the number of channels while expanding the gain of signal to each channel so as to achieve clients more remote away. The reverse is also conceivable. For instance, when a client gets more near to a cell site, the number of channels will increase and the modulation can also change to expand the bandwidth. The upshot is that cells ought to be considerably less sensitive to over-burden and cell size shrinkage during the load than before. In a perfect world, clients at any range ought to get strong QOS without drops that 
3G innovation may involvement. Here is an inside and out Q\&A on OFDMA®. The $802.16 \mathrm{e}$ variant of WiMAX additionally support for multiple-input-multiple-output (MIMO) reception apparatus innovation and Beam forming and Advanced Antenna Systems (AAS), which are all "smart" antenna advances that altogether enhance gain of WiMAX systems as well as throughput. The 802.16e standard is being used fundamentally in licensed range for unadulterated mobile applications. Many firms have chosen to build up the 802.16e standard only for both fixed and versatile forms. The 802.16e adaptation of WiMAX is the nearest practically identical innovation to the developing LTE mobile remote standard. Or, then again rather, it is more legitimate to state that LTE is the most practically identical to mobile WiMAX as far as capacities and also innovation. The two contending advancements are truly particularly similar in fact.

\section{WIMAX PHYSICAL LAYER}

The WiMAX physical layer depends on orthogonal frequency division multiplexing. OFDM is the transmission plan of decision to empower fast information, video, and mixed media interchanges and is utilized by an assortment of business broadband frameworks, including DSL, Wi-Fi and Digital Video Broadcast Handheld (DVB-H), and Media FLO, other than WiMAX. OFDM is a rich and productive plan for high information rate transmission in a non-line-of-sight or multipath radio condition.

\subsection{OFDM TECHNOLOGY}

Orthogonal frequency division multiplexing (OFDM) innovation furnishes administrators with a proficient intends to beat the difficulties of NLOS propagation. In FDM, guard bands are expected to decrease the interference between various frequencies, which causes bandwidth wastage in this manner, it is not a spectrum efficient and financially savvy arrangement. In any case, OFDM is a more range effective technique that evacuates all the guard bands yet keeps the modulated signals orthogonal to moderate the interference level [5]. As shown in Fig.4, the required bandwidth in OFDM is fundamentally diminished by separating multiple modulated carrier closed until the point when they are really overlapping. OFDM utilizes Fast Fourier Transform (FFT) and inverse FFT to change over serial information to various channels. The FFT size 256, which implies an aggregate number of 256 sub channels (carriers) are characterized for OFDM. In OFDM, the original signal is divided into 256 subcarriers and transmitted in parallel. Consequently, OFDM is referred to as a multicarrier modulation scheme. Contrasted with single-carrier schemes, OFDM is more robust against multipath propagation delay inferable from the utilization of smaller subcarriers with low bit rates bringing about long symbol periods. A guard time is acquainted at each OFDM symbol with additionally alleviate the impact of multipath delay spread.
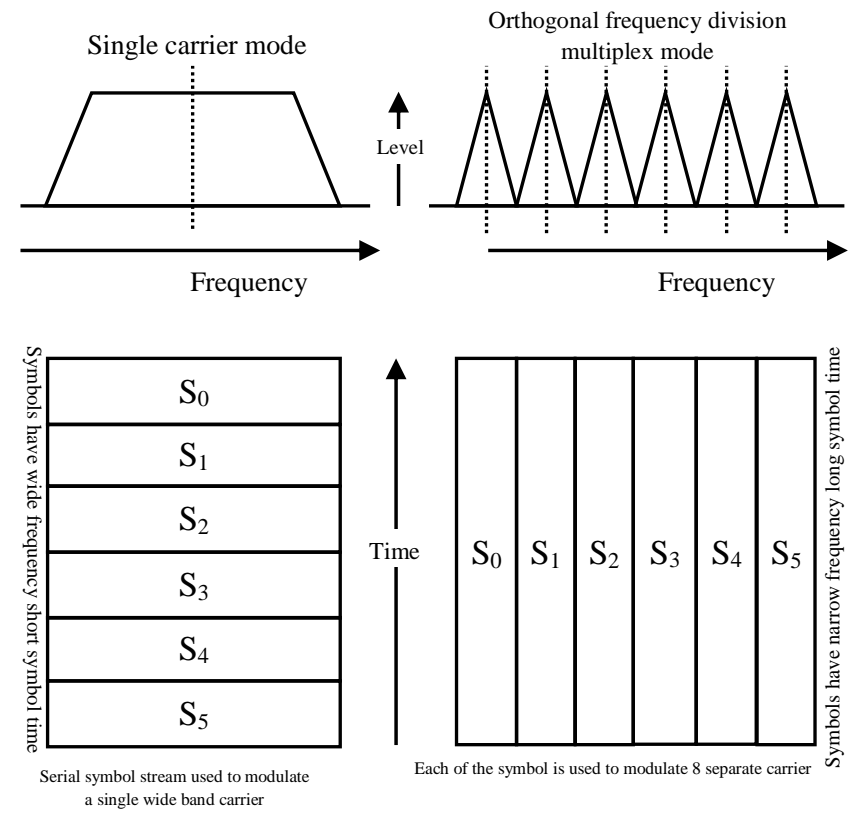

Fig.4. OFDM Technology

The WiMAX OFDM waveform offers the advantage of having the capacity to work with the larger delay spread of the NLOS condition. By virtue of the OFDM symbol time and utilization of a cyclic prefix, the OFDM waveform disposes of the between Inter Symbol Interference (ISI) issues and the complexities of adaptive equalization. Since the OFDM waveform is made out of various narrowband orthogonal carriers, selective fading is restricted to a subset of carriers that are moderately simple to equalize. An example, it is taken as a correlation between an OFDM signal and a single carrier signal, with the data being sent in parallel for OFDM and in series for single carrier. The ability to remove delay spread, multi-path, and ISI in a proficient way takes into consideration higher information rate throughput. For example it is simpler to equalize the individual OFDM carriers than it is to equalize the broader single carrier signal. For these reasons recent worldwide standards, for example, those set by IEEE 802.16, ETSI BRAN, and ETRI, have built up OFDM as the favored innovation of choices.

\subsection{OFDM PARAMETERS IN WIMAX}

As specified previously, the fixed and mobile versions of WiMAX have somewhat extraordinary usage of the OFDM physical layer. Fixed WiMAX, which depends on IEEE 802.162004, utilizes a 256 FFT-based OFDM physical layer. Mobile WiMAX, which depends on the IEEE 802.16e-2005 standard, utilizes a scalable OFDMA-based physical layer. On account of mobile WiMAX, the FFT sizes can vary from 128 bits to 2,048 bits.

\subsubsection{Fixed WiMAX OFDM-PHY:}

For fixed WiMAX the size of FFT is taken as 256 which is fixed and in which 192 subcarrier are used for information convey and 8 as pilot subcarrier uses for synchronization and channel estimation and rest are used as guard band sub carrier. In fixed FFT size the subcarrier spacing is changes with change in channel bandwidth. With larger bandwidth, the subcarrier spacing 
increases and symbol time decreases. Decreasing symbol time shows that larger part is guard time and it is used to remove delay spread.

\subsubsection{Mobile WiMAX OFDMA-PHY:}

In mobile WiMAX, the FFT size is not fixed. It is scalable from 128 to 2,048. Here, with the expansion of bandwidth, the FFT size is additionally increased to such an extent that the subcarrier division is constantly $10.94 \mathrm{kHz}$. This fixes the OFDM symbol time, thusly scaling have insignificant effect on higher layers. The $10.94 \mathrm{kHz}$ subcarrier spacing was taken to maintain the delay spread and Doppler spread needs for working in mixed, fixed and mobile situations. This subcarrier spacing can help delay spread values up to $20 \mu$ s and vehicular mobility up to $125 \mathrm{kmph}$ while working in $3.5 \mathrm{GHz}$. The $10.94 \mathrm{kHz}$ of subcarrier spacing shows that $128,512,1,024$, and 2,048 FFT are used for channel data bandwidth of $1.25 \mathrm{MHz}, 5 \mathrm{MHz}, 10 \mathrm{MHz}$, and $20 \mathrm{MHz}$, individually.

\subsection{SUB CHANNELIZATION OFDMA}

Sub Channelization in the uplink is a choice within WiMAX. Without sub channelization, administrative limitations and the requirement for cost effective CPEs, ordinarily cause the link budget to be asymmetrical, this causes the system range to be uplink restricted. Sub channeling empowers the link budget to be balanced such that the system gain are similar for both up and down links. Sub channeling concentrates the transmit power into fewer OFDM carriers; this is what that expands the system gain that can either be utilized to extend the reach of the system, remove the building penetration losses, or potentially diminish the power consumption of the CPE. The utilization of sub channeling is additionally extended in orthogonal frequency division multiple access (OFDMA) to empower a more adaptable utilization of resources that can support nomadic or mobile operation.

\subsection{MAC-LAYER OVERVIEW}

The WiMAX MAC layer is used to provide an interface between the higher transport layers and the physical layer. The MAC layer composes the MAC service data units (MSDUs) packets from higher level into MAC protocol data units (MPDUs) for transmission through the air. And do vice versa for receiving. The IEEE 802.16-2004 and IEEE 802.16e-2005 MAC configuration incorporates a convergence sub layer for interface with higher-layer protocols, for example, ATM, TDM Voice, Ethernet, IP, and any upcoming future convention. Given the prevalence of IP and Ethernet in the business, the WiMAX Forum has decided to help only IP and Ethernet at this time. The convergence sub layer suppressed the MSDU header to decrease the higher layer overheads on each packet, other than provide a mapping to and from the higher layers. The WiMAX MAC is supported the high peak bit rates while conveying QoS like ATM and DOCSIS. The WiMAX MAC offers lot of flexibility using a variable-length MPDU for effective transmission. To save PHY overhead, the various MPDUs of same or different lengths might be totaled into a single burst. In same way, to save MAC header overhead, the different MSDUs from the same higher-layer administration might be linked into a single MPDU. Then again, larger MSDUs might be divided into smaller MPDUs and sent over various frames. The MAC payload is encrypted and prefixed with a generic MAC header (GMH) that contains a connection identifier (CID). The MAC payload have a transport or a management message. Other than MSDUs, the transport payload may send Automatic Repeat Request (ARQ).

\subsubsection{Channel-Access Mechanisms:}

In WiMAX, at the base station (BS), MAC layer allocates the bandwidth to all subscribers, in both the uplink and the downlink. When multiple sessions or connections with base station have occur then the mobile station (MS) has allocated the bandwidth. In that situation, the base station allocates bandwidth to the mobile stations in the aggregate, after that MS allocates it among the multiple connections. All other scheduling on the downlink and uplink is finished by the base station. For the downlink without including the MS, the BS allocates the bandwidth to each MS based on the requirement of the congestion and for the uplink the allocation is based on the demands from the MS. The WiMAX standard provides the facility by which MS can request and get bandwidth. The BS uses polling in which it allocates the bandwidth to MS through dedicated or shared basis. WiMAX characterizes a contention access and resolution system for the situation when multiple MS uses shared slot [9].

\subsection{POWER CONTROL}

Power control programs are utilized to enhance the overall execution of the systems; it is used by the base station to sending power control information for the control of power level to all Customer Premise Equipments (CPEs). With the help of this controlled power level CPE transmits enough power to dynamical changing environment conditions. The power control decreases the overall power utilization of the CPE and the potential interference with other BSs. The transmit power of the CPE is approximately related to its distance from the BS in line-of-sight communication and for non-line-of-sight communication it is subject to the clearance and interferences.

\subsection{ADAPTIVE MODULATION}

Adaptive modulation permits the WiMAX systems to adjust the modulation schemes based on SNR of radio link. At the point when the radio link is high in quality then for providing more capacity to system, the highest modulation schemes are used. During signal attenuation, the WiMAX can move to a lower modulation schemes to keep the connection quality and link stability. This facility enables the system to remove the time selective fading. The key component of adaptive modulation is that it builds the range that a higher modulation schemes can be utilized over, since the system can change to the genuine attenuation conditions, rather than having a fixed plan that is planned for the most pessimistic situations.

\subsection{ERROR CORRECTION TECHNIQUES}

For error correction in WiMAX techniques, we use the Strong Reed Solomon FEC, convolution encoding, and interleaving algorithms. These techniques are helpful to find the error frames which are lost due to frequency selective fading or burst errors.

\subsection{QUALITY OF SERVICE (QOS)}

Voice capacity is crucial, particularly in global markets where fewer services are available. Therefore the IEEE 802.16a standard provides QoS that includes voice and video for a low-latency 
network. The grant/request features of the 802.16 Media Access Controller (MAC) empowers an administrator to at the same time give premium ensured levels of service to organizations. For various applications, it is important that the network layer should assure the sufficient QoS in terms of data rate, delay and bandwidth but actually it is hard to provide such kind of assurance in a wireless systems as they are susceptible to error. In order to fulfill this situation the multipath routing has been used. This routing can provide good Qos than the single path [14].

\subsection{SECURITY}

Privacy and encryption features are included in the 802.16 standard to support secure transmissions and provide authentication and data encryption.

\section{COMPETING TECHNOLOGIES}

Inside the commercial places, WiMAX's main rivalry originates from generally used wireless networks with merging functionality for example, UMTS and CDMA2000, and in addition various Internet-oriented networks, for example, HIPERMAN and WiBro. The two noteworthy 3G networks, CDMA2000 and UMTS are competitor of WiMAX because both provides DSL-class Internet access, notwithstanding telephone benefit. UMTS has also been upgraded to compete specifically with WiMAX as UMTS-TDD, which can utilize WiMAX oriented range, and it gives a more reliable (less bandwidth requirement at peak) clients experience than WiMAX (Fig.5). Advancing, comparative air interface innovations to those utilized by WiMAX are being taken as the $4 \mathrm{G}$ improvement of UMTS [12].

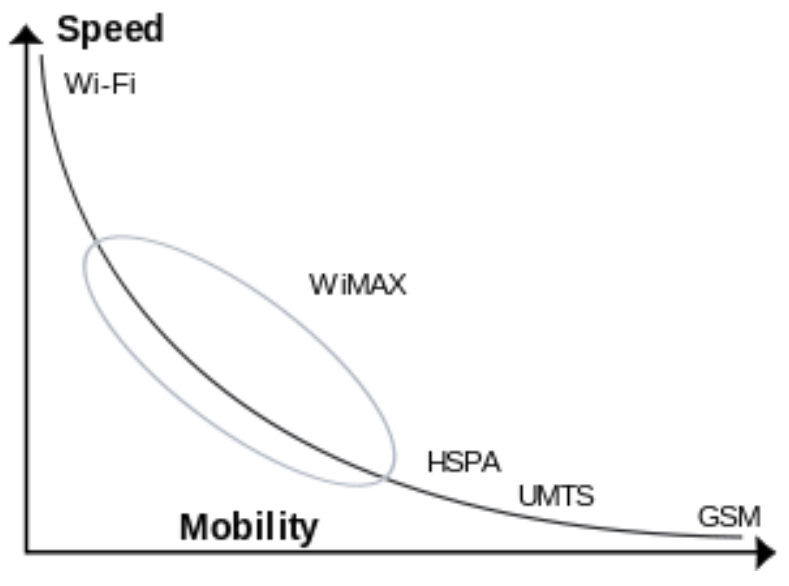

Fig.5. Comparison of different Wireless technologies

\subsection{WIBRO}

WiBro (wireless broadband) is an Internet technology being designed by the Korean telecom industry. In February 2002, the Korean government allocated $100 \mathrm{MHz}$ of electromagnetic spectrum in the $2.3 \mathrm{GHz}$ band, and in late 2004, WiBro Phase 1 was standardized by the TTA (Telecommunications Technology Association) of Korea. WiBro is the newest variety of mobile wireless broadband access. It is based on the same IEEE 802.16 standard as WiMAX but is designed to maintain connectivity on the movement, tracking a receiver at speeds of up to 37 mile per $\mathrm{hr}(60 \mathrm{~km} / \mathrm{hr})$ [7].

\section{COMPARISON BETWEEN WIMAX AND WI- FI}

Undoubtedly, WiMAX and Wi-Fi are corresponding innovations and will remain so for years. The broadly accessible Wi-Fi innovation utilized as a part of hotspots in hotels, organizations, air ports, institutions and larger Wi-Fi zones in some urban areas will keep on growing for a long time. The current whirlwind of city Wi-Fi mesh network systems has just served to bond the innovation into the wireless condition. Wi-Fi isn't leaving at any point in the near future [4].

Table.2. Comparison between WiMAX and Wi-Fi

\begin{tabular}{|c|c|c|c|}
\hline \multicolumn{4}{|c|}{ Comparison between Wimax and Wi-Fi Technologies } \\
\hline $\begin{array}{l}\text { Parameters } \\
\text { for } \\
\text { comparison }\end{array}$ & $\begin{array}{l}\text { WiMAX(IE } \\
\text { EE 802.16) }\end{array}$ & $\begin{array}{c}\mathrm{Wi}-\mathrm{Fi} \\
\text { (IEEE802. } \\
\text { 11b) }\end{array}$ & $\begin{array}{c}\text { Wi-Fi } \\
(\text { IEEE802.11a/g) }\end{array}$ \\
\hline Basic uses & $\begin{array}{c}\text { Broadband } \\
\text { wireless } \\
\text { access }\end{array}$ & $\begin{array}{l}\text { Wireless } \\
\text { LAN }\end{array}$ & Wireless LAN \\
\hline $\begin{array}{l}\text { Frequency } \\
\text { band }\end{array}$ & $\begin{array}{c}\text { Licensed/unl } \\
\text { icensed 2-11 } \\
\mathrm{GHz}\end{array}$ & $\begin{array}{l}2.4 \mathrm{GHz} \\
\mathrm{ISM}\end{array}$ & $\begin{array}{r}2.4 \mathrm{GHz} \text { ISM (g) } \\
5 \mathrm{GHz} \text { NII (a) }\end{array}$ \\
\hline $\begin{array}{c}\text { Channel } \\
\text { bandwidth }\end{array}$ & $\begin{array}{l}\text { Adjustable } \\
1.25-20 \mathrm{MHz}\end{array}$ & $25 \mathrm{MHz}$ & $20 \mathrm{MHz}$ \\
\hline $\begin{array}{c}\text { Half/full } \\
\text { duplex }\end{array}$ & Full & Half & Half \\
\hline $\begin{array}{c}\text { Radio } \\
\text { Technology }\end{array}$ & $\begin{array}{c}\text { OFDM (256 } \\
\text { channels) }\end{array}$ & DSSS & OFDM (64-channels) \\
\hline $\begin{array}{l}\text { Bandwidth } \\
\text { efficiency }\end{array}$ & $<5 \mathrm{bps} / \mathrm{Hz}$ & $\begin{array}{c}<0.44 \\
\mathrm{bps} / \mathrm{Hz}\end{array}$ & $<2.7 \mathrm{bps} / \mathrm{Hz}$ \\
\hline Modulation & $\begin{array}{c}\text { BPSK, } \\
\text { QPSK,16,64, } \\
\text { 256 QAM }\end{array}$ & QPSK & $\begin{array}{c}\text { BPSK,QPSK,16-,64- } \\
\text { QAM }\end{array}$ \\
\hline FEC & $\begin{array}{c}\text { Convolution } \\
\text { code, Reed } \\
\text { Solomon }\end{array}$ & None & Convolution code \\
\hline Encryption & Mandatory & Optional & Optional \\
\hline $\begin{array}{c}\text { Access } \\
\text { protocol }\end{array}$ & $\begin{array}{c}\text { Request/Gra } \\
\mathrm{nt} \\
\end{array}$ & CSMA/CA & CSMA/CA \\
\hline Mobility & $\begin{array}{c}\text { Mobile } \\
\text { WiMAX } \\
(802.16 \mathrm{e})\end{array}$ & $\begin{array}{c}\text { In } \\
\text { developme } \\
\text { nt }\end{array}$ & In development \\
\hline Mesh & Yes & \begin{tabular}{|c|} 
Vendor \\
proprietary
\end{tabular} & Vendor proprietary \\
\hline
\end{tabular}

As the WiMAX standard develops with Clear wire in 2009 and keeps gain acknowledgment and drive cost reductions, new chipsets that join the capacity to work over various stages will turn out to be more typical as MAN segment of this system innovation gradually being changed over more complex WiMAX networks, as the business cases for hotspot. Essentially, this implies WiMAX clients in a couple of years will have the capacity to not just access Wi-Fi hotspots at a cafe, yet could have mobile citywide WiMAX access also, alongside access to other existing cellular innovations. In any cases, other LAN innovations for 
example UHF Whitespace frequencies, Bluetooth, Ultra wideband and the $802.11 \mathrm{n}$ networks that provide coverage in shorter range hotspot systems will all develop and require chipsets and laptop radios that will inevitably have the capacity to consistently cross these shorter range information systems and in addition to cellular systems and WiMAX citywide systems. The WiMAX standard is a major part of the very bright vision of the broadband wireless future that flexibility like this promises. We can summarize it with the help of above Table. 2.

\section{BENEFITS OF WIMAX}

Component Suppliers,

- Guaranteed wide market acceptance of developed components

- Lower manufacturing costs because of economies of scale

- Reduced hazards because of interoperability Equipment Manufacturers

- Stable supply of minimal effort segments and chips

- Freedom to concentrate on improvement of system elements predictable with center capabilities, while realizing that equipment will interoperate with outsider items

- Engineering development efficiencies

- Lower manufacturing costs because of economies of scale Operators and Service Providers

- Lower CAPEX - with bring down cost base station, customer premises equipment (CPE), and system organization costs

- Lower investment risk because of flexibility of decision among different sellers and solutions

- Ability to tailor system to particular applications by mixing and coordinating equipment from various vendors

- Improved operator business case with lower OPEX End Users

- Lower subscriber expenses

- Wider selection of terminals empowering cost performance analysis

- Portability of terminals while moving areas/networks from WiMAX administrator " $\mathrm{A}$ " to administrator " $\mathrm{B}$ "

- Lower service rates after some time because of cost efficiencies in the conveyance chain.

\section{LIMITATIONS}

A usually held misinterpretation is that WiMAX will convey $70 \mathrm{Mbit} / \mathrm{s}$ more than $50 \mathrm{~km}$. In all actuality, WiMAX can do either working over greatest range $(50 \mathrm{~km})$ builds bit error rate and in this manner must utilize a lower bit rate. Bringing down the range enables a gadget to work at higher bit rates. Ordinarily, fixed WiMAX systems have a higher-increase directional reception apparatus introduced close to the customer (client) which brings about significantly expanded range and throughput. Portable WiMAX systems are generally made of indoor "customer premises equipment" (CPE, for example, desktop modems, tablets with coordinated Mobile WiMAX or other Mobile
WiMAX gadgets. Portable WiMAX gadgets ordinarily have an omni-directional antenna which is of lower-pick up contrasted with directional reception apparatuses yet are more compact. Practically speaking, this implies in a viewable pathway condition with a portable Mobile WiMAX CPE, speed of 10Mbit/s at $10 \mathrm{~km}$ could be conveyed However, in urban situations they might not have line-of-sight and along these lines clients may just get $10 \mathrm{Mbit} / \mathrm{s}$ more than $2 \mathrm{~km}$. Higher-increase directional antenna can be utilized with a Mobile WiMAX connect with range and throughput benefits however the undeniable loss of viable portability.

\section{FUTURE OF WIMAX}

\subsection{THE IEEE 802.20 STANDARD}

The IEEE 802.20 standard is a broadband remote systems service innovation that is being institutionalized for sending by versatile interchanges specialist co-ops, in parts of their licensed range. The limit of 802.20 is anticipated to be $2 \mathrm{Mbps}$ per client, and its range is similar to $3 \mathrm{G}$ cell innovations, to be specific, up to $5 \mathrm{~km}$. More common place organizations will be in the area of 1 to $3 \mathrm{~km}$. Finish of the 802.20 standard is not expected soon. The 802.20 standard has been a work in progress since late 2002, yet the going has been moderate, most definitely. 802.20 and $802.16 \mathrm{e}$, the versatile WiMAX detail, seems comparable at first look yet contrast in the frequencies they will utilize and the advancements they depend on. Standard 802.20 will work underneath $3.5 \mathrm{GHz}$, though portable WiMAX will work inside the $2 \mathrm{GHz}$ to $6 \mathrm{GHz}$ groups. Further, as the name recommends, 802.16e depends on WiMAX, with the objective of having WiMAX transmitters having the capacity to help both fixed and portable associations. Despite the fact that the 802.20 group will be back at work later, the 802.20 innovation is charming, with guarantees of low-idleness $1 \mathrm{Mbps}$ connections being managed even at rates of up to $150 \mathrm{mph}$, however we will need to wait for two or three years for it.

\subsection{IEEE 802.16M}

The $802.16 \mathrm{~m}$ portable WiMAX standard is a follow on to 802.16e standard and is a contender to the International Telecom Union's (ITU) thought as an IMT advanced (4G) innovation particularly, giving downlink speeds of no less than $100 \mathrm{Mbps}$ in a wide range with high-mobility. The new $802.16 \mathrm{~m}$ standard will give expanded performance advantages more than $802.16 \mathrm{e}$. From an innovative viewpoint, $802.16 \mathrm{~m}$ is fit for giving up to $120 \mathrm{Mbps}$ down and 60Mbps up in an urban setting, utilizing $4 \times 2 \mathrm{MIMO}$ reception antennas on a single $20 \mathrm{MHz}$ wide expansive channel.

\section{CONCLUSION}

It is normal that WiMAX turns into the prevailing standard for Wireless MAN organizes on the planet showcase, at any rate, in fixed broadband systems. A short correlation in the vicinity of 802.16 and 802.16a has been given and furthermore it has been demonstrated the favorable position by utilizing versatile balance. It has been clarified that the key contrast between the underlying 802.16 standard and the 802.16a comprises of the regulation plan. The significance of OFDM has additionally been broke down and this turns into a vital element that has the effect between the 
802.16 and 802.16a standard. More about this subject can be found in the literature provided. PHY and MAC layers of WiMAX have been discussed future conceivable applications have been examined. WiMAX mobility standard is the subsequent stage. In any case, it will have its opposition too with the 802.20 standard that in short is called Mobility-Fi. We should check for the items and their execution in real situations to assess what the standard locations and the real performance of these products are. There are now models and furthermore advancement units utilizing WiMAX standard that are utilized for training and for the most part of research. These days, there are additionally a few items that have been brought into the market that as of now contains the WiMAX standard presented here. Market is the keyword to consider. Items should be conveyed by the market needs and those for end-clients should be greatly simple to introduce. Experience from DSL and link modems administrations demonstrates this disadvantage. Obviously, in addition to be easy to install and give great technical features, these products need to give low cost or possibly a reasonable advantage over different technologies that are, right now, already developed in the market like xDSL and cable modem.

\section{REFERENCES}

[1] IEEE 802.16e Task Group (Mobile Wireless MAN), Available at: http://www.ieee802.org/16/tge/.

[2] 802.16-2004 - IEEE Standard for Local and Metropolitan Area Networks Part 16: Air Interface for Fixed Broadband Wireless Access Systems, IEEE, 2004.

[3] C. Cicconetti, L. Lenzini, E. Mingozzi and C. Eklund, "Quality of Service Support in IEEE 802.16 Networks", IEEE Network, Vol. 8, No. 2, pp. 50-55, 2006.

[4] Vasile Horia Muntean and Marius Otesteanu, "WiMAX versus LTE - An Overview of Technical Aspects for Next Generation Networks Technologies", Proceedings of $9^{\text {th }}$ International Symposium on Electronics and Telecommunications, pp. 132-138, 2010.

[5] V. Singh and V. Sharma, "Efficient and Fair Scheduling of Uplink and Downlink in IEEE 802.16 OFDMA Networks", Proceedings of IEEE Wireless Communications and Networking Conference, pp. 29-37, 2006.

[6] Wimax forum, Available at: www.wimaxforum.org

[7] Ahmed Samy, Mohamed Hamdy and Noura Semary,, "Fast Forced Handover Technique for Load Balancing in Mobile
WiMAX for Real-time Applications", Proceedings of International Conference on Communication, Management and Information Technology, pp. 901-910, 2015.

[8] Wi-Max, Available at: http://electronicxtreme.blogspot.com/2006/12/wimax.html, Accessed on 2006.

[9] Wi-Max, Available http://news.techdirt.com/news/wirless/article/6929, Accessed on 2006.

[10] 21talks, Available at: http://21talks.net/voip/voiceoverwimax.

[11] S. Borst, "User-Level Performance of Channel-Aware Scheduling Algorithms in Wireless Data Networks", Proceedings of $22^{\text {nd }}$ Annual Joint Conference of the IEEE Computer and Communications Societies, pp. 44-47, 2003.

[12] Bo Li, Yang Qin, Chor Ping Low and Choon Lim Gwee, "A Survey on Mobile WiMAX [Wireless Broadband Access]", IEEE Communications Magazine, Vol. 45, No. 12, pp. 7075, 2007

[13] S. More and D.K. Mishra, "4G Revolution: WiMAX Technology", Proceedings of $3^{\text {rd }}$ International Conference on Asian Himalayas on Internet, pp. 110-116, 2013.

[14] Q. Zhang, W. Zhu and Y. Zhang, "End-to-End QoS for Video Delivery Over Wireless Internet", Proceedings of the IEEE, Vol. 93, No. 1, pp. 123-134, 2005.

[15] Jeffrey G. Andrews, Ghos and Muhammad Rias "Fundamental of WiMAX Understanding Broadband Wireless Networking", Prentice Hall, 2007.

[16] Howon Lee, T. Kwon, D Cho, G Lim and Y Chang, "Performance Analysis of Scheduling Algorithms for VoIP Services in IEEE 802.16e Systems", Proceedings of IEEE Vehicular Technology Conference, pp. 1231-1235, 2006.

[17] Kamal Ali Alezabi, Fazirulhisyam Hashim, Shaiful Jahari Hashim and Borhanuddin M. Ali, "A New Tunnelled EAP based Authentication Method for WiMAX Networks", Proceedings of IEEE Malaysia International Conference on Communications, pp. 412-417, 2013.

[18] D. Ma and M. Ma, "A QoS Oriented Vertical Handoff Scheme for WiMAX/WLAN Overlay Networks", IEEE Transactions on Parallel and Distributed Systems, Vol. 23, No. 4, pp. 598-606, 2012.

[19] W. Wang, X. Liu, J. Vicente and P. Mohapatra, "Integration Gain of Heterogeneous WiFi/WiMAX Networks", IEEE Transactions on Mobile Computing, Vol. 10, No. 8, pp. 1131-1143, 2011. 